\title{
Effects of Third Trimester Maternal Hemoglobin Upon Newborn Anthropometry
}

\author{
Madaan $\mathbf{G}^{1}$, Bhardwaj $\mathrm{AK}^{2}$, Narang $\mathrm{S}^{3}$, Sharma $\mathrm{PD}^{4}$ \\ ${ }^{1}$ Dr. Gautam Madaan, MBBS, MD Resident, ${ }^{2} \mathrm{Dr}$. \\ Anand Kumar Bhardwaj, MBBS, Dch.MD, Professor, \\ ${ }^{3} \mathrm{Dr}$. Sunny Narang, MBBS, MD, Assistant Professor, \\ ${ }^{4}$ Dr. PD Sharma, MBBS, MD, Professor and Head of \\ department. All from the department of Paediatrics, MM \\ University, MMIMSR, Mullana, Ambala, Punjab, India.
}

\section{Introduction}

$P$ regnant women are vulnerable to develop physiological and pathological anemia. Maternal anemia is a burden throughout the world, especially in developing countries. Maternal anemia is defined as a Hemoglobin $(\mathrm{Hb})$ level of $<11 \mathrm{~g} / \mathrm{dl}$, or Hematocrit $(\mathrm{Hct})$ of $<33 \%$ in all trimesters of pregnancy as defined by the World Health Organization (WHO) ${ }^{1}$.

Maternal anemia during pregnancy can lead to poor fetal outcome as risks of morbidity and mortality is increased. Several surveys found that maternal anemia was related to small sized baby ${ }^{2}$ and infant mortality. WHO reports that anemia affects nearly half of all pregnant women in developing world: $52 \%$ in developing countries and $23 \%$ in developed world ${ }^{3}$.

During pregnancy in women the hemoglobin concentration of the maternal blood falls from a nonpregnant average of about $13.3 \mathrm{~g} / \mathrm{dl}$ to an average of about $11.0 \mathrm{~g} / \mathrm{dl}$ at 36 weeks. The fall is steepest up to 20 weeks gestation, the concentration remains fairly constant up to 30 weeks and then rises slightly thereafter. Thus, any estimation of hemoglobin concentration taken after 20 weeks gestation will be reasonably representative of the fall induced by pregnancy ${ }^{4}$. Hence, hemoglobin levels of 3rd trimester of pregnancy were taken as a reference value throughout pregnancy in our study. Anemia is one of the most prevalent nutritional deficiency problems affecting pregnant women ${ }^{5}$. The high prevalence of iron deficiency among women during pregnancy in developing countries is of concern,

\begin{abstract}
Introduction: Maternal anemia during pregnancy can lead to poor fetal outcome as risks of morbidity and mortality is increased. Materials and Methods: All Singleton pregnancies delivered in MMIMSR, Mullana, Ambala from 5 April 2012 to 5 October 2012 fulfilling the criteria were included. The pregnant mothers were grouped into 4 categories according to the corresponding hemoglobin concentration: normal (=or>11), mild $(10.9-9.0 \mathrm{~g} / \mathrm{dl})$, moderate $(8.9-7.0 \mathrm{~g} / \mathrm{dl})$, and severe anemia (less than $7 \mathrm{~g} / \mathrm{dl}$ ). Results: Out of 334 pregnant women included in the study 249 $(74.6 \%)$ were found to be anemic. Among anemic mothers 9 had severe $(2.7 \%), 51$ had moderate $(15.3 \%)$ and 189 had mild (56.6) anemia. The anthropometric measurements (birth weight, length, chest circumference, head circumference) with decreasing severity of anemia showed statistically significant difference $(p=0.000$, $p=0.000, p=0.017, p=0.001$ ) respectively. It was seen that as the number of pregnancies (gravida) increases the severity of anemia increases with each pregnancy. Conclusion: Anemia during pregnancy negatively affected the anthropometric measurements of a newborn and severe anemia had significant negative effect on neonatal anthropometric measurements.
\end{abstract}

Key words: Maternal hemoglobin, Head circumference, Birth weight, Length, Chest circumference

and maternal anemia is still a cause of considerable perinatal morbidity and mortality ${ }^{6}$. The most common causes of anemia are poor nutrition, deficiencies of iron and other micronutrients, and malaria ${ }^{7}$. Sufficient maternal prenatal care during pregnancy by increasing mother's knowledge in nutrition and by supplementation of iron during pregnancy would be beneficial for both the mother and the neonate ${ }^{8}$.

\author{
Address for correspondence \\ Dr. Gautam Madaan \\ MM University, MMIMSR \\ House No; 349, Kidwai Nagar, Ludhiana-141003 \\ Punjab, India. \\ E-mail: gautammadan1985@live.in
}

This work is licensed under a Creative Commons Attribution 3.0 License.

\section{How to cite this article?}

Madaan G, Bhardwaj AK, Narang S, Sharma PD. Effects of Third Trimester Maternal Hemoglobin Upon Newborn Anthropometry. J Nepal Paediatr Soc 2013;33(3):186-189. 
Our study was designed to evaluate the correlation of $3^{\text {rd }}$ trimester $\mathrm{Hb}$ and neonatal anthropometry in Haryana.

\section{Materials and Methods}

This prospective study was conducted from 5 April 2012 to 5 October 2012. A total of 334 cases were included in the study. Maternal haemoglobin $(\mathrm{Hb})$ levels after 20 week of pregnancy were studied in relation to certain anthropometric parameters at birth in apparently normal pregnancies. The newborns birth weight, length, head and chest circumference, and gestational age were recorded. Mothers with hemoglobin concentration less than $11 \mathrm{~g} / \mathrm{dl}$ were taken as anemic according to WHO definition. The pregnant mothers were grouped into 4 categories according to the corresponding hemoglobin concentration: normal (=or>11), mild (10.9-9.0 g/dl), moderate $(8.9-7.0 \mathrm{~g} / \mathrm{dl})$ and severe anemic (less than $7 \mathrm{~g} / \mathrm{dl}$ ). The anthropometric measurements of newborns from non-anemic and anemic mother groups were compared. Gestational age was calculated from LMP and was confirmed by clinical examination. A multiple linear regression table was used to study associations between hemoglobin levels and anthropometric parameters. All the parameters were measured after 6 hours from birth to allow edema to subside and not more than 24 hours after delivery. All measurements were made by the same researchers. The neonates wore no clothes. All parameters were recorded as per standard protocol in Neonatal intensive care unit ${ }^{9}$. Each measure was recorded as the mean of 3 consecutive readings. Detailed medical and obstetric history of the mothers was recorded. Maternal complications known to influence fetal growth (i.e. hypertensive disorder of pregnancy, cardiac failure, acute or chronic infection, multiple pregnancy and metabolic disorders like diabetes mellitus) were excluded. Newborns with obvious congenital anomalies, hemolytic disease of the newborn were also excluded from the study. The babies were classified in relation to gestation. The data was thus collected, analyzed statistically. The tests of significance like Student's t-test and analysis of variance (ANOVA) and Chi square test were applied wherever required.

\section{Results}

Out of 334 pregnant women included in the study, $249(74.6 \%)$ were found to be anemic. Among anemic mothers 9 had severe (2.7\%), 51 had moderate (15.3\%) and 189 had mild (56.6) anemia. The anthropometric measurements (length, birth weight, chest circumference, head circumference) with decreasing severity of anemia showed statistically significant difference $(p=0.000$, $p=0.000, p=0.017, p=0.001$ ).

Table 1: Distribution of birth weight $(\mathrm{kg})$ of children according to hemoglobin level of mothers $(\mathrm{n}=334)$

\begin{tabular}{|l|c|c|c|c|c|}
\hline \multirow{2}{*}{ Hemoglobin Levels } & \multirow{2}{*}{ No. } & \multicolumn{4}{|c|}{ Birth weight (kg) } \\
\cline { 3 - 6 } & & Minimum & Maximum & Median & Mean \pm SD \\
\hline Severe & 9 & 1.2 & 3.4 & 2.4 & $2.2 \pm 0.8$ \\
\hline Moderate & 51 & 1.3 & 3.5 & 2.5 & $2.4 \pm 0.5$ \\
\hline Mild & 189 & 1.5 & 3.7 & 2.7 & $2.7 \pm 0.5$ \\
\hline Normal & 85 & 0.8 & 4.0 & 2.7 & $2.7 \pm 0.6$ \\
\hline
\end{tabular}

$\left(\mathrm{F}, \mathrm{p}\right.$-value $\left.-6.389,0.000^{*}\right)$

Table 2: Distribution of length (cm.) according to hemoglobin level of mothers $(n=334)$

\begin{tabular}{|l|c|c|c|c|c|}
\hline \multirow{2}{*}{ Hemoglobin level } & \multirow{2}{*}{ No. } & \multicolumn{4}{|c|}{ Length (cm) } \\
\cline { 3 - 6 } & & Minimum & Maximum & Median & Mean \pm SD \\
\hline Severe & 9 & 26.0 & 48.0 & 40.0 & $40.1 \pm 7.0$ \\
\hline Moderate & 51 & 27.0 & 51.0 & 47.0 & $45.7 \pm 4.5$ \\
\hline Mild & 189 & 30.0 & 57.0 & 48.0 & $47.4 \pm 3.2$ \\
\hline Normal & 85 & 38.0 & 56.0 & 48.0 & $47.4 \pm 2.7$ \\
\hline
\end{tabular}

(F, p-value - $\left.15.495,0.000^{*}\right)$

Table 3: Distribution of chest circumference ( $\mathrm{cm}$.) according to hemoglobin level of mothers $(\mathrm{n}=334)$

\begin{tabular}{|l|c|c|c|c|c|}
\hline \multirow{2}{*}{ Hemoglobin level } & \multirow{2}{*}{ No. } & \multicolumn{4}{|c|}{ Chest circumference (cm) } \\
\cline { 3 - 6 } & & Minimum & Maximum & Median & Mean \pm SD \\
\hline Severe & 9 & 21.0 & 32.0 & 31.0 & $28.9 \pm 3.9$ \\
\hline Moderate & 51 & 22.0 & 35.0 & 31.0 & $30.7 \pm 2.7$ \\
\hline Mild & 189 & 23.0 & 35.0 & 31.0 & $30.7 \pm 2.5$ \\
\hline Normal & 85 & 27.0 & 36.0 & 31.4 & $31.0 \pm 2.0$ \\
\hline
\end{tabular}

$\left(\mathrm{F}, \mathrm{p}\right.$-value $\left.-3.438,0.017^{*}\right)$ 
Table 4: Distribution of head circumference ( $\mathrm{cm}$.) according to hemoglobin level of mothers $(\mathrm{n}=334)$

\begin{tabular}{|l|c|c|c|c|c|}
\hline \multirow{2}{*}{ Hemoglobin level } & \multirow{2}{*}{ No. } & \multicolumn{4}{|c|}{ Head circumference (cm) } \\
\cline { 3 - 6 } & & Minimum & Maximum & Median & Mean \pm SD \\
\hline Severe & 9 & 25.0 & 35.0 & 33.0 & $31.4 \pm 3.8$ \\
\hline Moderate & 51 & 25.0 & 37.0 & 33.0 & $32.9 \pm 2.4$ \\
\hline Mild & 189 & 28.0 & 37.0 & 34.0 & $33.7 \pm 1.6$ \\
\hline Normal & 85 & 29.0 & 45.0 & 34.0 & $33.7 \pm 2.1$ \\
\hline
\end{tabular}

(F, p-value - $\left.5.490,0.001^{*}\right)$

\section{Discussion}

In developing countries, prevalence of anemia in pregnancy is reported to be $52 \%{ }^{6}$. In the study of Malhotra et.al. ${ }^{10}$ and Marti-Carvajal et.al. ${ }^{11}$, the overall prevalence of anemia among pregnant women was estimated to be $72.5 \%$, and $34.4 \%$ respectively. In our study, we found the prevalence of anemia in pregnant mothers to be $74.6 \%$. Among the mothers, $56.6 \%$ had mild, $15.3 \%$ had moderate, and $2.7 \%$ had severe anemia in our study. Among 630 pregnant women Marti-Carvajal et.al. ${ }^{11}$ found that $83 \%$ had mild, $15.2 \%$ had moderate, and $1.8 \%$ had severe anemia. In the study of Malhotra et.al. ${ }^{10}$ including 447 pregnant women, 31 of 447 (6.9\%) were found to be severely anemic. Geelhoed et $\mathrm{al}^{12}$ found that the average age of severely anemic mothers was 22 years, and $57 \%$ were nulliparous. In our study, severely anemic group the minimum hemoglobin level was found to be $5.1 \mathrm{~g} / \mathrm{dl}$, and $43.4 \%$ were nulliparous. Malhotra et.al. ${ }^{10}$, found severely anemic had 3 or more children, similar to our study.

These results may reflect the wide range of variations of prevalence and the degree of anemia in pregnant women from developing countries. It is clear that maternal anemia during pregnancy may have adverse affects on the fetus, and the anthropometric measurements of the neonate, however, the effect depends on the degree and severity of maternal anemia. In the study of Steer et al $^{13}$ evaluating 153,062 pregnant women, the highest average birth weight was found in the mother group with a hemoglobin concentration of 8.5-9.5 g/dl. We found that the highest birth weight belongs to the mother s with hemoglobin of 9-11 $\mathrm{g} / \mathrm{dl}$, suggesting the optimum minimum hemoglobin concentration for normal birth weight to be $9 \mathrm{~g} / \mathrm{dl}$. The data from our study pointed out that optimal maternal hemoglobin concentration during pregnancy that is lower than the accepted levels should be evaluated with further studies. A statistical significant difference was found in our study when anthropometric measurements were compared with that of mothers $\mathrm{Hb}$.

One study conducted by Godhia $\mathrm{M}^{14}$ et al showed that maternal third trimester hemoglobin concentration correlated with birth weight, length, of pre-term newborns only but our study showed that birth weight, length, head circumference were significant in both preterm, term and postterms.We found that as severity of anemia in third trimester decrease the mean birth weight of newborns increased from $2.4 \mathrm{~kg}$ to $2.7 \mathrm{~kg}$ where $\mathrm{p}$ value is highly significant $(<0.000)$ in table 1 but Hamalainen $\mathrm{Het} \mathrm{al}^{15}$ conducted study and concluded that third trimester anemia has no correlation rather it is the first trimester hemoglobin that affects the birth weight of newborns. In 2002, Brown et al observed that third-trimester maternal $\mathrm{Hb}$ did not predict weight, length or $\mathrm{HC}$ of the newborn but it did predict newborn's ponderal index.Our study showed that birth weight, height, head circumference and chest circumference were affected by third trimester hemoglobin. It was seen in our study as the severity of anemia decreased the mean length of the babies increased from $40.1 \mathrm{~cm}$ to $47.4 \mathrm{~cm}$ and $p$ value is found to be significant. Similar results were seen with chest circumference and head circumference.

Our study has some limitations: Firstly, since it was performed in a single center, and the sample size is not so big, it may not be representative of the whole population. Secondly, mothers were not categorized for some other maternal factors like low height and body mass index, which could contribute to low birth weight.

\section{Conclusion}

To summarize, our study showed that maternal anemia during pregnancy negatively affected the anthropometric measurements of the neonates. However, the severe form of maternal anemia has the most significant effect. A randomized, nationwide, multi-center study incorporating other maternal factors, like body height and body mass index may yield more representative results of the whole population.

Acknowledgements: None

Funding: None

Conflict of interest: None

Permission from IRB: Yes 


\section{References}

1. Tippawan Liabsuetrakul, Is international or Asian criteria-based Body Mass Index associated with maternal anaemia, low birth weight, and preterm births among Thai Population? - An Observational Study. J Health Popul Nutr 2011;29(3):218-28.

2. Philip $\mathrm{J}$ Steer. Maternal hemoglobin concentration and birth weight 1'2'3. Am J Clin Nutr 2000;71(5):1285s-1287s.

3. Steer P, Alam M, Wadsworth J, Welch A. Relation between maternal haemoglobin concentration and birth weight in different ethnic groups. BMJ 1995;310:489-91.

4. Telatar B, Comert S, Vitrinel A, Erginoz E, Akin Y. The effect of maternal anemia on anthropometric measurements of newborn. Saudi Med J 2009;30(3):409-12.

5. Thangaleela T, Vijayalakshmi P. Prevalence of anaemia in pregnancy. Ind J Nutr Diet 1994;31:2629.

6. Cutner A, Bead R, Harding J. Failed response to treat anaemia in pregnancy: reasons and evaluation. J Obstet Gynecol 1999; suppl.:S23-7.

7. UNICEF/UNU/WHO. Iron deficiency anaemia: assessment, prevention, and control. A guide for program managers. Geneva, Switzerland: World Health Organization; 2001.

8. Zimmermann MB, Hurrell RF. Nutritional iron deficiency. Lancet 2007;370:511-20.
9. Deasi AB, Mukherjee D. Growth and Development: Basic concepts. In: Parthasarathy A. IAP Textbook of Pediatrics $4^{\text {th }}$ ed. NEW DELHI: Jaypee: 2010. p80-82.

10. Malhotra M, Sharma JB, Batra S, Sharma S, Murthy NS, Arora R. Maternal and perinatal outcome in varying degrees of anemia. Int J Gynaecol Obstet 2002;79:93-100.

11. Marti-Carvajal A, Pena-Marti G, Comunian G, Munoz S. Prevalence of anemia during pregnancy: results of Valencia (Venezuela) anemia during pregnancy study. Arch Latinoam Nutr 2002;52:5-11.

12. Geelhoed D, Agadzi F, Visser L, Ablordeppey $\mathrm{E}$, Asare K, O'Rourke $\mathrm{P}$, et al. Severe anemia in pregnancy in rural Ghana: a case-control study of causes and management. Acta Obstet Gynecol Scand 2006;85:1165-171.

13. Steer P, Alam MA, Wadsworth J, Welch A. Relation between maternal haemoglobin concentration and birth weight indifferent ethnic groups. BMJ 1995;310:489-91.

14. Godhia M, Nigudkar M, Desai R. Associations between maternal nutritional characteristics and the anthropometric indices of their full-term and preterm newborns. Pak J Nutr 2012;11(4): 343-349.

15. Hamalainen $H$, Hakkarainen $K$, Heinonen $S$. Anaemia in the first but not in the second or third trimester is a risk factor for low birth weight. Clin Nutr 2003;22(3):271-75 